\title{
The Whole-Brain $\mathrm{N}$-Acetylaspartate Correlates with Education in Normal Adults
}

\author{
Lidia Glodzika , William E. Wu ${ }^{b}$, James S. Babb², Lutz Achtnichts ${ }^{c}$, Michael Amann ${ }^{\mathrm{c}, e}$, Marc \\ Sollberger ${ }^{c, d}$, Andreas U. Monsch ${ }^{d}$, Achim Gass ${ }^{c}$, and Oded Gonen ${ }^{b}$
}

${ }^{1}$ Department of Psychiatry, New York University School of Medicine, New York, NY, USA bDepartment of Radiology, New York University School of Medicine, New York, NY, USA 'Department of Neurology, University Hospital Basel, Petersgraben 4, CH-4031 Basel, Switzerland dDepartment of Geriatrics, University Hospital Basel, Petersgraben 4, CH-4031 Basel, Switzerland eDepartment of Neuroradiology, University Hospital Basel, Petersgraben 4, $\mathrm{CH}-4031$ Basel, Switzerland

\begin{abstract}
$N$-acetylaspartate (NAA) is an index of neuronal integrity. We hypothesized that in healthy subjects its whole brain concentration (WBNAA) may be related to formal educational attainment, a common proxy for cognitive reserve. To test this hypothesis 97 middle aged to elderly subjects (51-89 years old, 38\% women) underwent brain MRI and non-localizing proton spectroscopy. Their WBNAA was obtained by dividing their whole-head NAA amount with the brain volume. Intracranial volume and fractional brain volume, a metric of brain atrophy, were also determined. Each subject's educational attainment was the sum of their years of formal education. In the entire group higher education was associated with larger intracranial volume. The relationship between WBNAA and education was observed only in younger (51-70 years old) participants. In this group education explained $21 \%$ variance in WBNAA. More WBNAA was related to more years of formal education in adults and younger elders. Prospective studies can determine whether this relationship reflects a true advantage from years of training versus innate characteristic predisposing to higher achievements later in life. We offer that late life WBNAA may be more affected by other like factors acting at midlife and later.
\end{abstract}

\section{Keywords}

Brain; Brain-volume; Cognitive Reserve; Education; MR spectroscopy; $N$-acetylaspartate

\section{Introduction}

At $0.1 \%$ of the brain's wet weight (Birken and Olendorf, 1989) the $N$-acetylaspartate (NAA) is the second most abundant amino acid in the mammalian brain. Although NAA's precise role(s) remain controversial, its almost exclusive sequestration in neurons and the coupling

(C) 2012 Elsevier Ireland Ltd. All rights reserved.

Corresponding Author/Reprints requests: Oded Gonen, PhD, Department of Radiology, New York University School of Medicine, 660 First Avenue, $4^{\text {th }}$ Floor, New York, New York 10016, Tel.: (212) 263-3532, FAX: (212) 263-7541, oded.gonen@nyumc.org.

Publisher's Disclaimer: This is a PDF file of an unedited manuscript that has been accepted for publication. As a service to our customers we are providing this early version of the manuscript. The manuscript will undergo copyediting, typesetting, and review of the resulting proof before it is published in its final citable form. Please note that during the production process errors may be discovered which could affect the content, and all legal disclaimers that apply to the journal pertain. 
of its synthesis to energy production in mitochondria, make it a suitable marker of neuronal integrity (Moffett et al., 2007).

Among the resonances identified in proton MR spectroscopy $\left({ }^{1} \mathrm{H}-\mathrm{MRS}\right)$ none has yielded more diagnostic information than the NAA whose concentration declines in most focal or diffuse brain disorders (Schuff et al., 2006). Relative to the abundant evidence of NAA reductions across many diseases (Schuff et al., 2006; Moffett et al., 2007) its physiological role in healthy subjects still requires elucidation (Rigotti et al., 2007). However, there is a growing body of work demonstrating convincing associations between a variety of neuropsychological tests or general cognitive abilities and NAA in healthy populations (Ross and Sachdev, 2004). Both occipito-parietal white matter NAA (Jung et al., 1999; Jung et al., 2000) and fontal cortical NAA (Pfleiderer et al., 2004) were positively related to an intelligence quotient - IQ. There also are reports on associations between medial temporal lobe NAA and memory (Gimenez et al., 2004) or NAA concentration in centrum semiovale and executive functions (Charlton et al., 2007). Given the connection between NAA levels and neuronal density or mitochondrial energy production, these mostly positive NAAcognition associations are not surprising. Nonetheless, recent evidence indicates that not always more NAA correlates with higher IQ. Jung at al. observed that lower right anterior gray matter NAA predicted better verbal IQ while higher right posterior gray matter NAA predicted better performance IQ, suggesting that increased neuronal number or greater energy production, may not be sufficient to explain superior cognitive performance. Some other hypothesis i.e. neural efficiency must be taken into account (Jung et al., 2009).

General cognitive capacities are closely related to educational achievement (Gottfredson, 1997; Yeo et al., 2011). However education is also seen as a common proxy for cognitive (active) reserve (Stern et al., 1994). The "reserve" hypothesis conjectures the existence of factors modulating the relationship between cognitive decline and brain pathology. These factors are seen both as passive (brain size) or active (cognition, compensation) phenomena. The last ones imply a high functioning of intact neural tissue, possibly as a result of acquired functional changes of neural networks (Stern, 2002). Unfortunately, biological underpinnings of an active reserve are poorly understood. Changes in tissue composition (higher levels of markers indicative of neuronal metabolic health such as NAA) could conceivably reflect more efficient network utilization, making NAA potential index of a built-up reserve. Education is related to a more complex dendritic system and denser interneuronal connections (Jacobs et al., 1993). Since these tissue changes may be reflected by NAA (Moffett et al., 2007), higher education could be related to higher NAA concentration. However, we are unaware of any report on the relationship between education and NAA.

In this study we tested the hypothesis that in cognitively healthy middle aged and elderly whole brain NAA (WBNAA) concentration is related to their formal educational attainment. Moreover, since it remains unclear to what extent education reflects predominantly general intellectual capacity (Yeo et al., 2011) and to what extent it may be a marker of actively built-up reserve, we also we examined relationships between the general mental ability $(g)$, education and brain metrics.

\section{Methods}

\subsection{Human Subjects}

Ninety seven ( 37 women, 60 men) cognitively healthy subjects: $71.7 \pm 8.2$ (mean \pm standard deviation; range: 51-89) years old were recruited at the outpatient Memory clinic of the Basel University Hospital, and gave written informed consent to the Institutional Review Board approved protocol. They were volunteering as controls for ongoing studies. Major 
depression was ruled out according to the ICD-10 criteria (World Health Organization 1992). Cognitive abilities were assessed with the Mini Mental State Examination [MMSE (Folstein et al., 1975)] and the battery of tests including the California Verbal Learning Test (Delis et al., 1987), the CERAD Neuropsychological Assessment Battery (Morris et al., 1989); the Rey-Osterrieth Complex Figure (Schreiber et al., 1999), Digit Span and Corsi Blocks (Wechsler, 1987), a computerized test of attention (Zimmerman and Fimm, 1994), the Stroop Color-Word Interference Test (Perret, 1974), the Trail Making Test, part A \& B (Army, 1944), phonemic fluency tests (Thurstone, 1938), the Clock Drawing Test (Thalmann et al., 2002), Boston Naming Test (Kaplan et al., 1983) and Design Fluency (Regard et al., 1982).

To confirm subjects' preserved cognitive status a knowledgeable informant was questioned using the modified Informant Questionnaire on Cognitive Decline in the Elderly (IQ-CODE) (Ehrensperger et al., 2010). For inclusion in the study, subjects' demographically adjusted standard scores had to be within normal limits. All subjects were well functioning with a MMSE score of $29.2 \pm 0.9$ (mean \pm standard deviation, range: $26-30$ ) and in good general health.

\subsection{Education}

Each subject's formal educational attainment was the sum of their years in elementary school, gymnasium (secondary or apprenticeship schools), university and subsequent advanced degrees.

\subsection{General mental ability $g$}

The general mental ability $g$ was estimated based on factor analysis of neuropsychological tests. The z-scores of the following tests were entered in factors analysis: California Verbal Learning Test (Delis et al., 1987), Digit Span and Corsi Blocks (Wechsler, 1987), the Stroop Color-Word Interference Test (Perret, 1974), the Trail Making Test, part A \& B (Army, 1944), phonemic fluency tests (Thurstone, 1938), Boston naming Test (Kaplan et al., 1983) and Design Fluency (Regard et al., 1982). The first unrotated factor was extracted and served as a $g$ approximation. The selection was guided by the availability of $\mathrm{z}$-scores. Data was available for 91 participants.

\subsection{Imaging}

2.4.1. MRI-All MR experiments were done in a $3 \mathrm{~T}$ scanner (Magnetom Allegra (Siemens AG, Erlangen, Germany) using its manufacturer-provided transmit-receive head-coil. Field homogeneity was then adjusted with our chemical-shift-imaging based auto-shim procedure to yield a consistent $27 \pm 4 \mathrm{~Hz}$ head water linewidth across our cohort (Hu et al., 1995). This was followed by sagittal Magnetization-Prepared-Rapid-Acquisition-Gradient-Echo (MPRAGE): TE/TR/TI=3.49/2150/1000 ms, $7^{\circ}$ flip angle, 144 slices $1.1 \mathrm{~mm}$ thick, $256 \times 224$ matrix, $256 \times 224 \mathrm{~mm}^{2}$ field-of-view MRI.

2.4.2. Image segmentation - Brain volumetry-Brain parenchyma volume, $V_{B}$, was segmented from MP-RAGE images using our in-house FireVoxel package (Mikheev et al., 2008). It starts by automatic placement of a seed region in periventricular WM to obtain its signal intensity, $I_{W M}$ (see Fig. 1a). Following selection of all pixels at or above 0.55 of $I_{W M}$, a brain mask is constructed for each slice. Pixels of intensity below $0.55 I_{W M}$ were defined as CSF (cerebrospinal fluid). The masks were truncated at the foramen magnum to include the stem and cerebellum and $V_{B}$ was the product of the number of pixels in the mask by their volume. The precision of the process was established at 3.4\% for T1-weighted MRI (Rusinek and Chandra, 1993). 
A hard threshold for tissue segmentation could have caused a systematic bias toward younger brains, since T1 contrast in MP-RAGE usually deteriorates with age. To exclude this possibility we examined relationships between contrast and age in sample of 53 subjects with demographics (age, gender, education) comparable to our study group. Signal intensity we extracted from the seed $\left(I_{W M}\right.$ seed) and the CSF $\left(I_{C S F}\right)$. CSF region of interest was placed in lateral ventricles away from choroid plexus. For each subject we calculated factor $g$ as: $I_{C S F} / I_{W M}$ seed. There was no correlation between $g$ and age (rho=.06, $p=.66$ ) or $g$ and $V_{B}($ rho $=.09, p=.52)$.

Intracranial volumes, $V_{I C}$, were obtained from the MP-RAGE images using MRIcro, a free downloadable package: http://www.mricro.com (Rorden and Brett, 2000). The extracted brain was then used to calculate the $V_{I C}$ (see Fig. 1b) and the fractional brain parenchyma volume (fBPV) defined as $V_{B} / V_{I C} \times 100 \%$.

2.4.3. MR spectroscopy - WBNAA quantification-The global NAA amount, $Q_{\mathrm{NAA}}$, was obtained with a non-localizing TE/TI/ TR $=0 / 940 / 10^{4} \mathrm{~ms}{ }^{1} \mathrm{H}$-MRS sequence (Gonen et al., 1998). Its $\mathrm{TR} \gg T_{1}$ and $\mathrm{TE} \approx 0$ ensure insensitivity to $T_{1}$ and $T_{2}$ variations. Absolute quantification was done against a reference $3 \mathrm{~L}$ sphere of $1.5 \times 10^{-2}$ mole NAA in water. Subject and reference NAA peak areas, $S_{\mathrm{S}}$ and $S_{R}$, were obtained by manual phasing and selection of the NAA peak limits, followed by peak area integration all using our in-house graphic interactive software written in IDL (Research Systems Inc. Boulder CO) (Fig. 1c). It was performed by four operators blinded to each other's result. A result more than two average standard deviations (for the four readers' over all the patients, $\sim 8 \%$ ) from the mean for that patient, was rejected. If more than one was rejected than that entire set was excluded as "poor quality." Subject and phantom NAA peak areas, $S_{\mathrm{S}}$ (shown in Fig. 1c) and $S_{R}$, were obtained by integration and $Q_{\mathrm{NAA}}$ estimated as (Gonen et al., 1998):

$$
Q_{\mathrm{NAA}}=1.5 \times 10^{-2} \cdot \frac{S_{\mathrm{S}}}{S_{\mathrm{R}}} \cdot \frac{V_{\mathrm{S}}^{180^{\circ}}}{V_{\mathrm{R}}^{180^{\circ}}} \text { moles, } \quad[1]
$$

where $V_{\mathrm{R}}^{180^{\circ}}$ and $V_{\mathrm{s}}^{180^{\circ}}$ are the transmitter voltages for non-selective $1 \mathrm{~ms} 180^{\circ}$ inversion pulses on the reference and subject, reflecting relative coil loading and by reciprocity the sensitivity.

To normalize inter-subject head size variations, $Q_{N A A}$ was divided by the brain parenchyma volume $\left(V_{B}\right)$, to yield the brain size independent whole-brain NAA concentration:

$$
\text { WBNAA }=Q_{N A A} / V_{B} \quad \mathrm{mM}, \quad[2]
$$

Its inter- and intra-subject variability has been previously shown to be $\pm 8 \%$ (Rigotti et al., 2007).

\subsection{Statistical analyses}

Between-group comparisons were carried with t-test, correlations checked with Pearson correlation coefficient $(r)$ or when data did not meet the assumption of normality with $\mathrm{U}$ Mann-Whitney test and Spearman correlation coefficient, respectively. An association between education (independent variable) and WBNAA, $V_{I C}$, fBPV and $g$ (dependent variables) was tested in linear regression models. For each relationship (education-WBNAA, education- $V_{I C}$, and education-fBPV) separate combinations of models were created incorporating age, gender, education and interactions between them. Model with the best fit was chosen for each relationship. Similarly, the associations between $g$ (dependent variable) and WBNAA, $V_{I C}$, and fBPV (independent variables) were also tested in separate 
combinations of models which incorporated age, gender, education and interactions between them.

\section{Results}

Our cohort had on average $13.3 \pm 2.8$ years of education (mean \pm standard deviation), $13.1 \pm 3.1 \mathrm{mM}$ WBNAA, $1424 \pm 134 \mathrm{ml} V_{I C}$ and $74.5 \pm 4.6 \% \mathrm{fBPV}$. Older subjects had lower $\mathrm{fBPV}(\mathrm{r}=-0.59, p<0.001)$ and MMSE $(\mathrm{rho}=-0.40, p<0.001)$. Women were younger $\left(\mathrm{t}_{[95]}=2.7, p<.01\right)$. After accounting for age females still had higher fBPV $\left(\mathrm{F}=15.1_{[2,94]}\right.$, $p<0.001)$, lower $V_{I C}\left(\mathrm{~F}=67.2_{[2,94]}, p<0.001\right)$ and fewer years of education $(\mathrm{Z}=-2.8, \mathrm{p}<.01)$. WBNAA and MMSE did not differ between genders (Table 1). Education was not related to age. There was no correlation between WBNAA and ICV, WBNAA and fBPV or WBNAA and $V_{B}$.

\subsection{Education and $V_{I C}$}

The model with the best fit $\left(\mathrm{F}=36.04_{[2,94]}, p<0.001\right)$ included gender $(\beta=-0.55, p<0.001)$ and education $(\beta=0.24, p=0.004)$. Both male gender and more years of education were associated with higher $V_{I C}$.

\subsection{Education and fBPV}

The final model $\left(\mathrm{F}=36.03_{[2,94]}, p<.001\right)$ included age $(\beta=-0.50, p<.001)$ and gender $(\beta=0.31$, $p<.001)$. Being younger and female was associated with higher fBPV. Education was not related to $\mathrm{fBPV}$.

\subsection{Education and WBNAA}

The final model with the best fit $\left(\mathrm{F}=3.2_{[3,93]}, p=0.03\right)$ included age $(\beta=0.90 p=0.04)$, education $(\beta=1.90, p=0.01)$, and interaction between them $(\beta=-1.98, p=0.02)$, thus indicating that the relationship between WBNAA and education is different in different age groups. To further test this hypothesis we tested the relationship between education and WBNAA in younger $(<71)$ and older $(\geq 71)$ individuals (split at the median). Among younger subjects education $(\beta=0.46, p=0.002)$ was strongly related to WBNAA (model: $\left.\mathrm{F}=11.0_{[1,41]}, p=0.002\right)$. In this group education explained $21 \%$ variance in WBNAA. There was no relationship between education and WBNAA in older participants (Fig. 2). Interestingly younger and older groups did not differ in WBNAA (Table 2). The relationship between WBNAA and education remained unchanged when fBPV, $V_{I C}$ or $V_{B}$ were incorporated into the model.

\subsection{Education and $g$}

The model with the best fit $\left(\mathrm{F}=3.4_{[2,88]}, p=0.04\right)$ included education $(\beta=0.21, p=0.04)$ and age $(\beta=-0.19 p=0.07)$. General intellectual capacities positively correlated with education, but explained only $5 \%$ of $g$ variance. Age marginally contributed to the model.

\section{5. $g$ and brain metrics}

We did not find any relationships between $g$ and WBNAA, ICV or fBPV.

\section{Discussion}

In this study, we show that education was associated with larger intracranial volume and higher WBNAA, possibly reflecting higher neuronal integrity in individuals with higher education. Since higher WBNAA may represent more intricate tissue structure (Moffett et 
al., 2007), our results may reflect a more complex dendritic system and denser interneuronal connections, previously reported in connection with higher education (Jacobs et al., 1993).

Consequently, WBNAA could be a biological substrate of cognitive reserve conferred by education. Since WBNAA loss is reported in mild cognitive impairment and Alzheimer's disease (Falini et al., 2005), an individual's higher "baseline" could delay clinical manifestation of disease, in line with the broadly accepted protective effects of education. However, we must emphasize that this conjecture is only speculative.

In our group the relationship between WBNAA and education was strong among younger(51-70) participants but absent in the older group. This is a puzzling finding. However, it is possible that factors other than education affect WBNAA later in life. Occupational attainment, leisure and physical activities in middle and later life are believed to help build up reserve (Scarmeas and Stern, 2003). Conceivably these factors may have greater contribution to WBNAA later in life than education acquired at a younger age. Second, as can be expected older subjects had more brain atrophy than younger ones. Even though the concentration of NAA in the remaining tissue seems to stay the same across age groups (Wu et al., 2012), atrophy might have affected the relationship between NAA and education through mechanisms not related to NAA concentration (selective atrophy of tracts or regions). Different distribution of NAA and education in the age groups could also have contributed to different slopes. This is however unlikely, since variances were not statistically different. Finally, unequal gender distribution more women in the younger group) could explain different relationships between NAA and education in our age groups.

In line with previous observations (Deary, 2012) we found a relationship between general intellectual capacity $g$ and total years of education. The connection although significant was weak with education accounting for about $5 \%$ in variance in general cognitive abilities. A current review pointed out that correlation between intelligence and education varied quite substantially across studies, depending on measures used to assess either variable (Deary, 2012). It is thus possible that the nature of measures used in this study can explain the weak association. Most interestingly, we did not observe any relationship between $g$ and any brain metrics, especially WBNAA. A few reasons might have caused it. First, it is possible that number and type of tests used did not allow for most accurate estimation of $g$. Second, the relationship between $g$ and NAA is better explained by regional than global indices. This is especially possible in the light of earlier finding by Jung et al. (Jung et al., 2009), who showed in the same individuals both negative and positive correlations between IQ and NAA depending of the region examined. It would then follow that these differences could cancel each other out at the global level. Finally, although we admit it is only a hypothesis, a higher WBNAA (presumably representing denser or healthier neurons) in our group might have been proactively built-up early on in life with the help of education. This would be consistent with the notion of plasticity. Indeed both we and others have previously reported on NAA increases in relation to presumable cortical reorganization like recovery from stroke (Glodzik-Sobanska et al., 2007) or changes in temporal cortex related to musical activity (Aydin et al., 2005), in support of a dynamic nature of NAA. Another recent study revealed hippocampal NAA increases after 4 months of spatial navigation training. These increases were transient and disappeared 4 months after discontinuation of the training protocol, indicating that more permanent changes may be necessary to maintain higher NAA levels (Lovden et al., 2011). Plausibly, years of education could introduce such permanent and diffuse changes. Still, given previously reported strong links education- IQ (Gottfredson, 1997) and IQ -NAA (Pfleiderer et al., 2004) a higher capacity from birth most likely led to higher educational achievements. The removal of this ambiguity would require a longitudinal study from pre-school through up to $20+$ years of formal education and a cohort large enough to rule out various confounds. These requirements coupled with the 
transience of modern society and MR technology render such study difficult, therefore, unlikely.

Among the volumetric metrics, only the $V_{I C}$, the marker of the original brain size, was related to education. The last finding also speaks in favor of higher education being an expression of higher congenital capacities. It does not disqualify, however, our hypothesis that it can also infer additional benefits, since WBNAA can be a marker both of quantity and quality of neural substrate. While the men had larger $V_{I C}$ than the women, they also had lower fBPV; findings pointing to more atrophy in males. Different levels of comorbidities could possibly explain these differences.

WBNAA did not correlate with $V_{B}$. Consequently $V_{B}$ did not influence the relationship between education and WBNAA. This is important since we normalized NAA to $V_{B}$, thus WBNAA variations could have been an artifact of variations in brain volume. We believe our results speak against this bias. Similarly, possible age- related differences in T1 contrast did not seem to play a significant role in our tissue segmentation and thus did not bias volume assessment.

Our study is also subject to several limitations inherent to its methodology. First, the 6-8\% sensitivity of WBNAA precludes detection of smaller changes (Rigotti et al., 2007). Second, subjects with clinically silent, "age appropriate" MRI abnormalities (i.e. white matter hyperintensities, cortical atrophy) were included. Third, since the study is not longitudinal, it is not possible to map the full WBNAA course. Our analyses may be limited by a relatively small sample size and lack of additional quantifiable metrics, e.g., life-long occupational attainment, or lifestyle activities that could modify existing relationships. As we pointed out earlier this information might have been especially useful in determining the correlates of WBNAA in our older group. Using a global metric we could not test whether NAA education relationship was driven by NAA concentrations in few brain regions or generalized changes in tissue integrity. This is an important issue since some evidence indicates that specific brain regions can be responsible for cognitive reserve (Stern et al., 2005). Also, since both variables (NAA and education) are highly complex our interpretation of their relationships might have been oversimplified. Finally, in our sample we had more men than women, which could have biased the results.

In conclusion, more formal education was related to higher WBNAA in adults and younger elders. Prospective studies can determine whether this relationship reflects a true advantage gained by more training or rather innate tissue characteristics that predispose an individual tohigher intellectual achievement. We offer that late life WBNAA may be more affected by other like factors acting at midlife and later.

\section{Acknowledgments}

This work was supported by NIH Grants NS050520, EB01015 and AG008051. We also gratefully acknowledge the financial support for this study from GlaxoSmithKline and the Novartis Foundation. We thank Ms. Elizabeth Pirraglia for her consultation.

\section{Abbreviations}

$\begin{array}{ll}\text { CERAD } & \text { Consortium to Establish a Registry for Alzheimer's Disease } \\ \text { CSF } & \text { cerebrospinal fluid } \\ \text { fBPV } & \text { fractional brain parenchyma volume } \\ { }^{1} \text { H-MRS } & \text { proton magnetic resonance spectroscopy }\end{array}$


IQ intelligence quotient

IQ-CODE Informant Questionnaire on Cognitive Decline in the Elderly

MMSE Mini Mental State Examination

MRI magnetic resonance imaging

NAA $\quad \mathrm{N}$-acetylaspartate

QNAA global NAA amount

$\mathbf{V}_{\mathbf{B}} \quad$ brain parenchyma volume

$\mathbf{V}_{\text {IC }} \quad$ intracranial volumes

WBNAA whole brain $\mathrm{N}$-acetylaspartate

WM white matter

\section{References}

Army. Army Individual Test battery Manual of Directions and Scoring. Washington, DC: War Department, Adjutant General's Office; 1944.

Aydin K, Ciftci K, Terzibasioglu E, Ozkan M, Demirtas A, Sencer S, Minareci O. Quantitative Proton MR Spectroscopic Findings of Cortical Reorganization in the Auditory Cortex of Musicians. American Journal of Neuroradiology. 2005; 26:128-136. [PubMed: 15661714]

Birken DL, Olendorf WH. N-acetyl-aspartic acid: a literature review of a compund prominent in $1 \mathrm{H}-$ NMR spectroscopic studies of the brain. Neuroscience \& Biobehavioral Reviews. 1989; 13:23-31. [PubMed: 2671831]

Charlton RA, McIntyre DJ, Howe FA, Morris RG, Markus HS. The relationship between white matter brain metabolites and cognition in normal aging: The GENIE study. Brain Research. 2007; 1164:108-116. [PubMed: 17632090]

Deary IJ. Intelligence. Annual Review of Psychology. 2012; 63:453-482.

Delis, DC.; Kramer, JH.; Kaplan, E.; Ober, BA. California Verbal Learning Test - Research Edition. New York: The Psychological Corporation; 1987.

Ehrensperger MM, Berres M, Taylor KI, Monsch AU. Screening properties of the German IQCODE with a two-year time frame in MCI and early Alzheimer's disease. International Psychogeriatrics. 2010; 22:91-100. [PubMed: 19747425]

Falini A, Bozzali M, Magnani G, Pero G, Gambini A, Benedetti B, Mossini R, Franceschi M, Comi G, Scotti G, Filippi M. A whole brain MR spectroscopy study from patients with Alzheimer's disease and mild cognitive impairment. Neuroimage. 2005; 26:1159-1163. [PubMed: 15878675]

Folstein MF, Folstein SE, McHugh PR. Mini-mental state: A practical method for grading the cognitive state of patients for the clinician. Journal of Psychiatric Research. 1975; 12:189-198. [PubMed: 1202204]

Gimenez M, Junque C, Narberhaus A, Caldu X, Segarra D, Vendrell P, Bargallo N, Mercader JM. Medial temporal MR spectroscopy is related to memory performance in normal adolescent subjects. NeuroReport. 2004; 15:703-707. [PubMed: 15094480]

Glodzik-Sobanska L, Li J, Mosconi L, Slowik A, Walecki J, Szczudlik A, Sobiecka B, de Leon MJ. Prefrontal N-acetylaspartate and post-stroke recovery: a longitudinal proton spectroscopy study. American Journal of Neuroradiology. 2007; 28:470-474. [PubMed: 17353314]

Gonen O, Viswanathan AK, Catalaa I, Babb JS, Udupa J, Grossman RI. Total brain N-acetylaspartate concentration in normal, age-grouped females: quantitation with non-echo proton NMR spectroscopy. Magnetic Resonance in Medicine. 1998; 40:684-689. [PubMed: 9797150]

Gottfredson LS. Why g matters: the complexity of everyday life. Intelligence. 1997; 24:79-132. 
Hu J, Javaid T, Arias-Mendoza F, Liu Z, McNamara R, Brown TR. A fast, reliable, automatic shimming procedure using $1 \mathrm{H}$ chemical-shift-imaging spectroscopy. Journal of Magnetic Resonance. 1995; 108:213-219. [PubMed: 7670755]

Jacobs B, Schall M, Scheibel AB. A quantitative dendritic analysis of Wernicke's area in humans. II. Gender, hemispheric and environmenatl factors. Journal of Comparative Neurology. 1993; 327:97-111. [PubMed: 8432910]

Jung RE, Brooks WM, Yeo RA, Chiulli SJ, Weers DC, Sibbitt WL. Biochemical markers of inteligence: a proton Mr spectroscopy study of normal human brain. The Royal Society, Proceedings: Biological Sciences. 1999; 266:1375-1379.

Jung RE, Gasparovic C, Chavez RS, Caprihan A, Barrow R, Yeo RA. Imaging intelligence with proton magnetic resonance spectroscopy. Intelligence. 2009; 37:192-198. [PubMed: 19936275]

Jung RE, Yeo RA, Chiulli SJ, Sibbitt WL, Brooks WM. Myths of neuropsychology: intelligence, neurometabolism, and cognitive ability. The Clinical Neuropsychologist. 2000; 14:535-545. [PubMed: 11262722]

Kaplan, E.; Goodglass, H.; Weintraub, S. Boston Naming Test. Philadelphia: Lea and Febiger; 1983.

Lovden M, Schaefer S, Noack H, Kanowski M, Kaufmann J, Tempelmann C, Bodammer NC, Kuhn S, Heinze HJ, Lindenberger U, Duzel E, Backman L. Performance-related increases in hippocampal $\mathrm{N}$-acetylaspartate (NAA) induced by spatial navigation training are restricted to BDNF Val homozygotes. Cerebral Cortex. 2011; 21 1435-14442.

Mikheev A, Nevsky G, Yitta S, Grosmann R, Rusinek H. Fully automated segmentation of the brain from T1-weighted MRI using Bridge Burner algorithm. Journal of Magnetic Resonance Imaging. 2008; 27:1235-1241. [PubMed: 18504741]

Moffett JR, Ross B, Arun P, Madhavarao CN, Namboodiri AMA. N-Acetylaspartate in the CNS: From neurodiagnostics to neurobiology. Progress in Neurobiology. 2007; 81:89-131. [PubMed: $17275978]$

Morris JC, Heyman A, Mohs RC, Hughes JP, van Belle G, Fillenbaum G, Mellits ED, Clark C. The consortium to establish a registry for Alzheimer's disease (CERAD). Part I. Clinical and neuropsychological assessment of Alzheimer's disease. Neurology. 1989; 39:1159-1165. [PubMed: 2771064]

Perret E. The left frontal lobe of man and the suppression of habitual responses in verbal categorical behaviour. Neuropsychologia. 1974; 12:323-330. [PubMed: 4421777]

Pfleiderer B, Ohrmann P, Suslow T, Wolgast M, Gerlach AL, Heindel W, Michael N. NAcetylasparate levels of left frontal cortex are associated with verbal intelligence in women but not men: a proton magnetic resonance spectroscopy study. Neuroscience. 2004; 123:1053-1058. [PubMed: 14751296]

Regard M, Strauss E, Knapp P. Children's production on verbal and non-verbal fluency tasks. Perceptual and Motor Skills. 1982; 55:839-844. [PubMed: 7162920]

Rigotti DJ, Inglese M, Babb JS, Rovaris M, Benedetti B, Filippi M, Grossman RI, Gonen O. Serial whole-brain $\mathrm{N}$-acetylasp.artate concentration in healthy young adults. American Journal of Neuroradiology. 2007; 28:1650-1651. [PubMed: 17893213]

Rorden C, Brett M. Stereotaxic display of brain lesions. Behavioural Neurology. 2000; 12:191-200. [PubMed: 11568431]

Ross A, Sachdev P. Magnetic resonance spectroscopy in cognitive research. Brain Research Reviews. 2004; 44:83-102. [PubMed: 15003387]

Rusinek H, Chandra R. Brain tissue volume measurement from magnetic resonance imaging: a phantom study. Investigative Radiology. 1993; 28:890-895. [PubMed: 8262742]

Scarmeas N, Stern Y. Cognitive Reserve and Lifestyle. Journal of Clinical Experimental Psychology. $2003 ; 25: 625-633$.

Schreiber HE, Javorsky DJ, Robinson JE, Stern RA. Rey-Osterrieth Complex Figure performance in adults with attention deficit hyperactivity disorder: a validation study of the Boston Qualitative Scoring System. Clinical Neuropsychology. 1999; 13:509-520.

Schuff N, Meyerhoff DJ, Mueller S, Chao L, Sacrey DT, Laxer K, Weiner MW. N-acetylaspartate as a marker of neuronal injury in neurodegenerative disease. Advances in Experimental Medicine and Biology. 2006; 576:241-262. [PubMed: 16802717] 
Stern Y. What is cognitive reserve? Theory and research application of the reserve concept. Journal of International Neuropsychological Society. 2002; 8:448-460.

Stern Y, Gurland B, Tatemichi TK, Tang MX, Wilder D, Mayeux R. Influence of education and occupation on the incidence of Alzheimer's disease. Journal of the American Medical Association. 1994; 271:1004-1010. [PubMed: 8139057]

Stern Y, Habeck C, Moeller J, Scarmeas N, Anderson KE, Hilton HJ, Flynn J, Sackeim HA, Van Hertuum RL. Brain networks associated with cognitive reserve in healthy young and old adults. Cerebral Cortex. 2005; 15:394-402. [PubMed: 15749983]

Thalmann B, Spiegel R, Stahelin HB. Dementia screening in general practice: simplified scoring for the Clock Drawing Test. Brain Aging. 2002; 2:36-43.

Thurstone, LL. Primary Mental Abilities. Chicago: University of Chicago Press; 1938.

Wechsler, D. Wechsler Memory Scale-Revised. San Antonio: Psychological Corporation/Harcourt Brace Javanovich; 1987.

World Health Organization. The ICD-10 classification of mental and behavioral disorder. Geneva: World Health Organization; 1992.

Wu W, Gass A, Glodzik L, Babb JS, Hirsch J, Sollberger M, Achtnichts L, Amann M, Monsch AU, Gonen $\mathrm{O}$. Whole brain $\mathrm{N}$-acetylaspartate concentration is conserved throughout normal aging. Neurobiology of Aging. 2012 Jan 12. (epub, ahead of print).

Yeo RA, Arden R, Jung RE. Alzheimer's Disease and Intelligence. Current Alzheimer's Research. $2011 ; 8: 345-353$.

Zimmerman, P.; Fimm, B. Testbatterie zur Aufmerksamkeitspruefung (TAP). Handbuch Version 1.02c. Wuerselen, Germany: Psytest; 1994. 

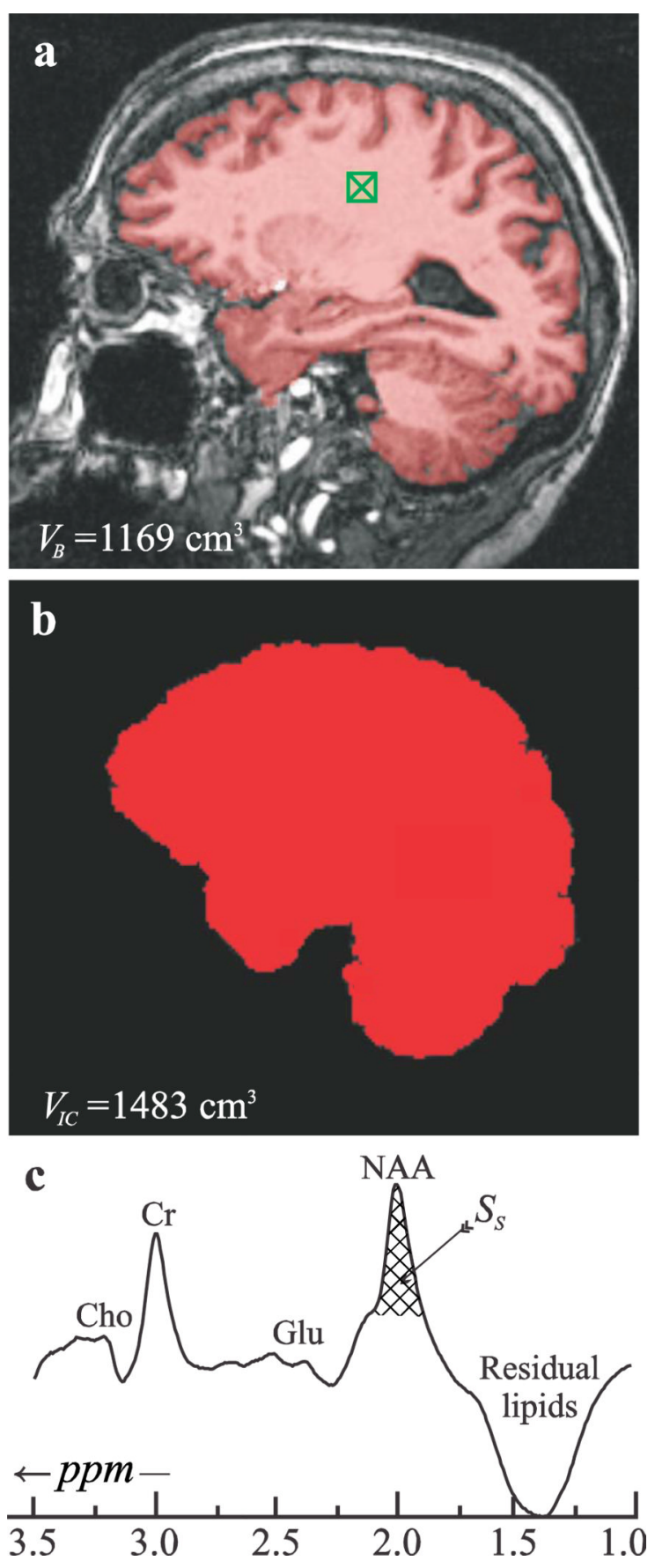

Fig. 1.

Top, a: MP-RAGE image from a 73 year old female overlaid with her $V_{B}$ (red). Note the "seed" in the WM (green hatched box) and FireVoxel's brain-capture performance. Center, b: Intra-cranial volume ( $\left.V_{I C}\right)$ segmentation of the same image with MRIcro. Note the inclusion of ventricular spaces but exclusion of skull and dura. Bottom, c: Whole-head ${ }^{1} \mathrm{H}-$ MR spectrum from the subject. $S_{S}$ (cross-hatched) is the integrated area of her NAA peak. Note the effective skull lipids signals suppression and that although other metabolites are visible in the spectrum, most notably the glutamate $(\mathrm{Glu})$, total creatine $(\mathrm{Cr})$ and total choline (Cho) signals, only the NAA is localized by its biochemistry mostly to the brain. 




Fig. 2.

Plot of the WBNAA versus formal education (years) in the older ( $\geq 71)(\mathbf{O})$, and younger $(<71)(\bigcirc)$ groups, superimposed with their respective regression (solid and dashed) lines.

Note the significant increase in WBNAA with education in the adults and "younger" elders. 
Table 1

Study variables (mean \pm standard deviation) by gender.

\begin{tabular}{|c|c|c|}
\hline Metric & Women $(N=37)$ & $\operatorname{Men}(N=60)$ \\
\hline Age (years) & $68.9 \pm 7.8^{*}$ & $73.4 \pm 8.0 *$ \\
\hline Education (years) & $12.4 \pm 2.8^{*}$ & $13.9 \pm 2.7^{*}$ \\
\hline MMSE (out of 30) & $29.4 \pm 1.0$ & $29.1 \pm 1.0$ \\
\hline$V_{I C}\left(\mathbf{c m}^{3}\right)$ & $1319.2 \pm 92.7^{*}$ & $1489.5 \pm 113.0$ * \\
\hline fBPV $(\%)$ & $77.1 \pm 3.8^{*}$ & $72.9 \pm 4.3^{*}$ \\
\hline WBNAA (mM) & $13.4 \pm 3.2$ & $13.0 \pm 3.0$ \\
\hline
\end{tabular}

Significantly different at $p<.01$. 
Table 2

Study variables (mean \pm standard deviation) by age group.

\begin{tabular}{|l|c|c|}
\hline Metric & Young $(N=\mathbf{4 3})$ & Old $(N=\mathbf{5 4})$ \\
\hline Age (years) & $\mathbf{6 4 . 3} \pm \mathbf{4 . 3}$ & $\mathbf{7 7 . 7} \pm \mathbf{5 . 0}$ \\
\hline Gender (\% female) & $\mathbf{5 1 \%}{ }^{* *}$ & $\mathbf{2 8 \%}$ \\
\hline Education (years) & $13.3 \pm 2.8$ & $13.4 \pm 2.9$ \\
\hline MMSE (out of 30) & $\mathbf{2 9 . 4 \pm 0 . 8}$ & $\mathbf{2 9 . 0 \pm 1 . 0}$ \\
\hline$V_{I C}\left(\mathbf{c m}^{\text {3 }}\right)$ & $1422.8 \pm 133.6$ & $1425.9 \pm 136.6$ \\
\hline fBPV $(\%)$ & $\mathbf{7 7 . 4} \pm \mathbf{3 . 4}$ & $\mathbf{7 2 . 2 \pm 4 . 1}$ \\
\hline WBNAA $(\mathbf{m M})$ & $13.4 \pm 3.1$ & $12.9 \pm 3.1$ \\
\hline
\end{tabular}

Significantly different at $p<.001$.

Significantly different at $p<.02$. 